UCRL-CR-123513

L-21581-1

Final Report to USAMP on the Use of EBPVD in the Light Metal Die Casting Industry

Glenn M. Heestand

RECEIVED

APR 181996

OSTI

February 2, 1996

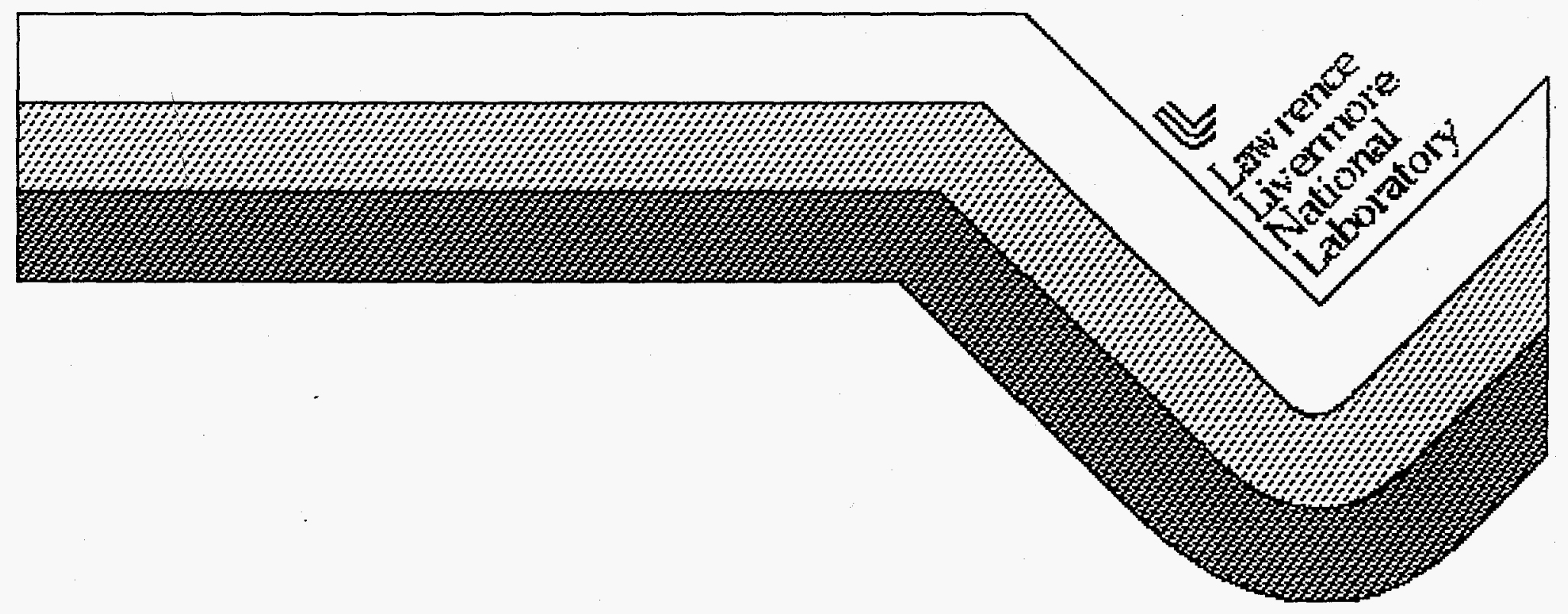

DISTRBBUTION OF THIS DOCUMENT is INLMMTED ph 


\section{DISCLAIMER}

This document was prepared as an account of work sponsored by an agency of the United States Government. Neither the United States Government nor the University of California nor any of their employees, makes any warranty, express or implied, or assumes any legal liability or responsibility for the accuracy, completeness, or usefulness of any information, apparatus, product, or process disclosed, or represents that its use would not infringe privately owned rights. Reference herein to any specific commercial product, process, or service by trade name, trademark, manufacturer, or otherwise, does not necessarily constitute or imply its endorsement, recommendation, or favoring by the United States Government or the University of California. The views and opinions of authors expressed herein do not necessarily state or reflect those of the United States Government or the University of California, and shall not be used for advertising or product endorsement purposes.

Work performed under the auspices of the U.S. Department of Energy by Lawrence Livermore National Laboratory under Contract W-7405-ENG-48. 


\title{
Final Report to USAMP on the Use of EBPVD in the Light Metal Die Casting Industry
}

\author{
Presented by: \\ Glenn M. Heestand \\ Lawrence Livermore National Laboratory \\ P.O. Box 808, L-460 \\ Livermore, California 94550
}

February 2, 1996

\section{Introduction}

This is the final report to the United States Automotive Materials Partnership (USAMP) on the use of Electron Beam Physical Vapor Deposition (EBPVD) to make rapid tooling for functional prototyping of metal mold processes. Historically this process has been successfully applied to the production of mold inserts for the plastics injection mold industry. Our approach for this project was to use the same technique to produce dies which could be used to make a few thousand light metal (aluminum and magnesium) prototype parts. The difficulty encountered in this project was that the requirements for the die casting industry, both in size and material requirements, were considerably more stringent than those encountered in the plastics injection industry. Consequently our technique, within the allotted time and budget constraints, was not able to meet the requirements set forth by USAMP.

The remainder of this report is organized into five sections. The first discusses the technique in some detail while the second discusses a successful application. The third section discusses issues with this process while the fourth specifically discusses the work done in this project. The last is a short summary and conclusion section.

\section{Technique}

Figure 1 is a highly schematic and simplified representation of the process. The first step is to produce a mandrel whose shape and size duplicates the object which is to be produced. The mandrel is then placed in an electron beam vaporizer where vapor is deposited on the mandrel. After a condensate of sufficient thickness is deposited, the mandrel and deposit are removed from the vaporizer where the mandrel and deposit are separated. The condensate shell, after some preparation, would then be attached to a mounting block ready for the casting process. 


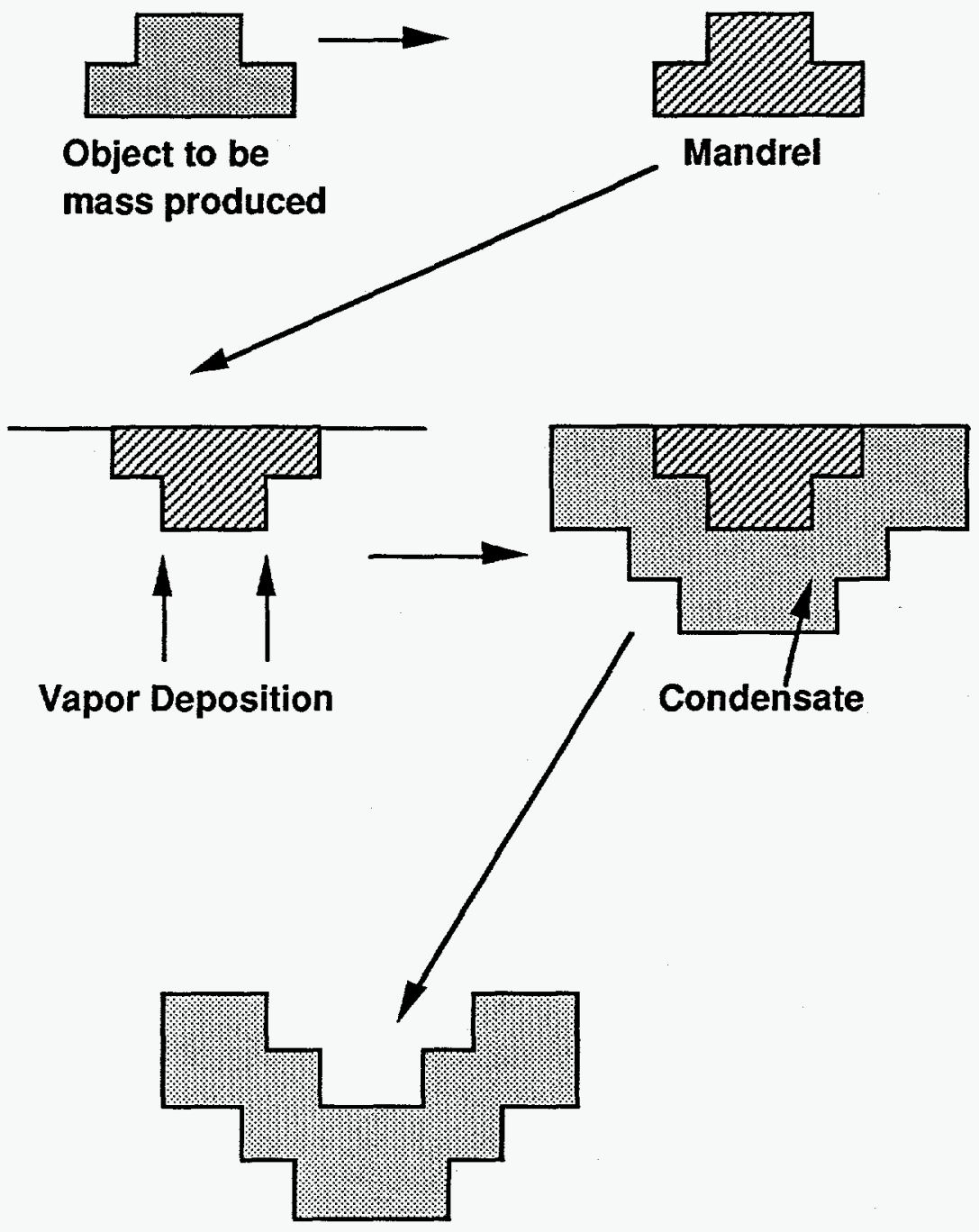

Mold Insert

Figure 1. Schematic of process used to produce dies using electron beam physical vapor deposition.

Figure 2 shows a schematic of the electron beam vaporizer used in this process. The mandrel to be coated is placed approximately $50 \mathrm{~cm}$ above the vapor source and is enclosed in a thermal package. This package, which consists of insulation, shielding and heaters, is used to control the substrate temperature both prior and during the coating process. The electron beam is incident from the left in Figure 2 and is bent onto the melt (material to be vaporized) surface by a local magnetic field (magnet pole faces not shown). Beam powers in this process are in excess of $100 \mathrm{~kW}$. A water cooled copper crucible is used to contain the melt. The feeder on the right replenishes the melt as material is vaporized. A water cooled copper enclosure contains the unused portion of the vapor and prevents it from accumulating on the stainless steel vessel walls. Operating pressures for this process are $\sim 5 \times 10^{-5}$ torr. 


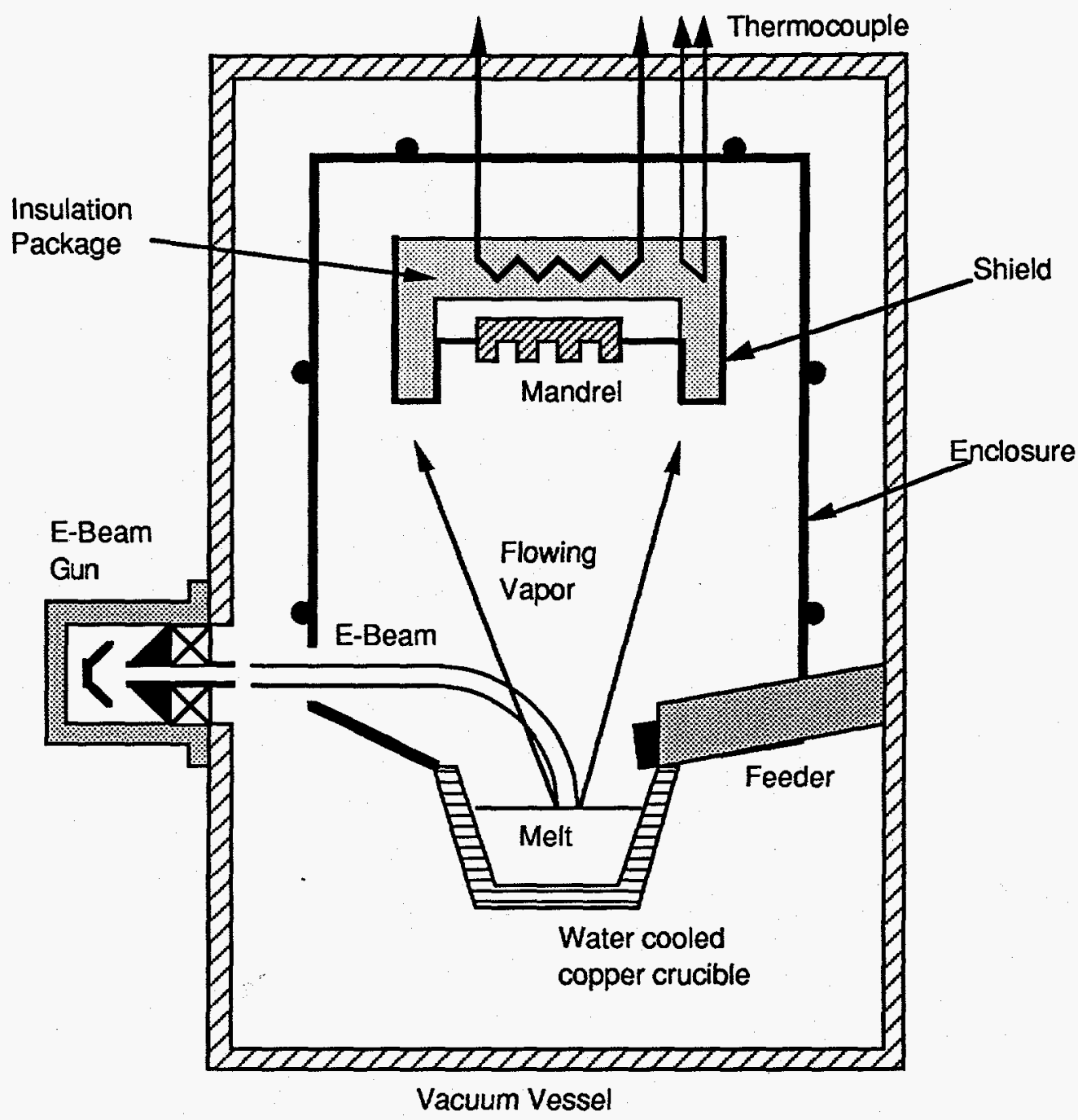

Figure 2. Schematic of electron beam vaporizer used to produce mold inserts for plastics injection molding industry or dies for the light metal die casting industry.

Figure 3 is an actual photograph of the apparatus. In this case the mandrel (located at the center of the picture) is graphite in the shape of a waffle iron approximately $8 \mathrm{~cm}$ on a side. The thermal package surrounding the mandrel is evident while the large plate at the bottom of the page is a magnetic pole face which provides the magnetic field used to bend the electron beam onto the melt. The waffle iron mandrel was used initially to do a proof-ofprincipal but was never tested in an injection molding machine.

The intense electron beam from the left is focused to spot on the melt and this spot is swept over the melt surface at $5 \mathrm{kHz}$ to generate a line approximately $1 \times 10 \mathrm{~cm}$. Within this line the local high average power density $\left(\sim 10^{4} \mathrm{~W} / \mathrm{cm}^{2}\right)$ is sufficient to vaporize the melt material: The vaporized material forms a jet of metal vapor atoms which is highly directional. Typically the vapor flux scales as $(\cos \theta) \mathrm{n} / \mathrm{r}^{2}$ where $\theta$ is measured with respect to the vertical, $r$ is the standoff or height of the mandrel above the melt and $n \sim 2-4$. For an assumed $\mathrm{n}$ of 3 and $50 \mathrm{~cm}$ standoff the perpendicular area where the flux is constant to within $10 \%$ is represented by a circle $9.5 \mathrm{~cm}$ in radius. A larger standoff yields a more even distribution over a given area but requires a larger vessel and longer coating times or higher evaporation rates to achieve a given thickness. 

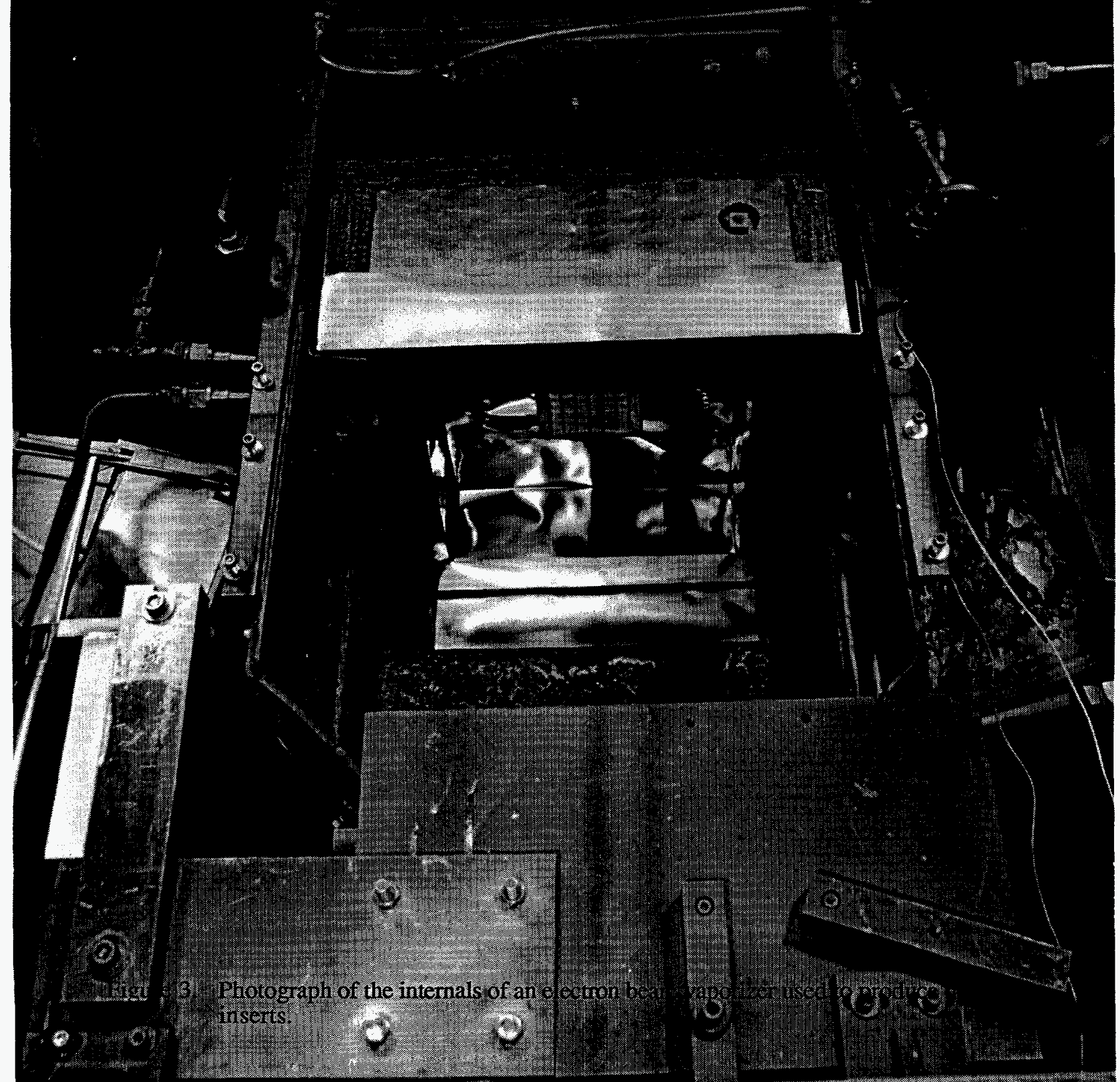
In the initial vaporization runs a nickel-aluminum-bronze alloy (C6300) was used as the evaporant. This is a good alloy for vaporization because the dominant constituents, $\mathrm{Al}$ and $\mathrm{Cu}$, have fairly high vapor pressures which are comparable. This means that the condensate stoichiometry should be close to that of the material being fed into the melt. It is difficult to maintain stoichiometry for alloys which have constituents with widely disparate vapor pressures. In general the low vapor pressure components tend to remain behind in the melt.

According to Movchan 1 one needs to operate the mandrel at temperatures which are on the order of half the melting temperature of the alloy being vaporized in order to achieve full density. Our experience shows that at high evaporation rates one must run closer to the alloy melting point than was suggested by Movchan's early work. For the aluminumbronze runs the mandrel was preheated to $1123 \mathrm{~K}$ and maintained at that temperature throughout the vaporization process. This is $\sim 85 \%$ of the melting point but was necessary to obtain good condensate microstructure and full density.

Following the preheating of the mandrel the electron beam gun is turned on and slowly brought up to full power and held there for a long duration ( $>10$ hours). At this power the evaporation rate for aluminum-bronze is $\sim 5 \mathrm{~kg} / \mathrm{h}$ but would be lower for low vapor pressure alloys. At a $50 \mathrm{~cm}$ standoff this produces a vapor density of $\sim 3.5 \times 10^{13}$ atoms $/ \mathrm{cm}^{2}$ which is sufficient to achieve a coating rate of $1.2 \mathrm{mils} / \mathrm{min}$. The duration of the run was sufficient to provided a total condensate thickness of one inch.

During the run the melt is fed at a rate to keep melt inventory constant. The feeder mechanism consists of a motor driven push rod system which pushes cylindrical feed bars to the melt edge where radiant heat and the skip electron beam melt the alloy causing it to drip into the melt. The feeder is replenished using a vacuum load locking mechanism.

Very often in high power electron beam vaporizers one observes spitting or the ejection of macroparticles from the melt surface. This often results from trapped gas bubbles within the melt which travel towards the surface and then explode. This can greatly effect coating uniformity and microstructure in an adverse way. For aluminum-bronze this was not observed but for 304 stainless, which contains trapped hydrogen, spitting was observed. Spitting can probably be mitigated by preheating the feedstock.

After the vaporization is complete the vessel is allowed to cool over night under vacuum. The next day the vessel is opened, the mandrel and deposit removed followed by a separation of the mandrel and deposit. Sometimes this separation requires the use of a parting agent such as boron nitride. Even then the separation is not always clean requiring minor light brushing to remove adhered graphite. As a final step the insert or die is drilled for water passages and mounted on an appropriate block for use in an injection molding machine.

\section{Successful Applications}

Since this process deposits condensate on an atom by atom basis it has the potential for reproducing very fine detail. To benchmark this technique a small business CRADA was established between LLNL and Laser Faire of Smithfield, $\mathrm{RI}^{2}$. As a test sample a graphite mandrel was machined to be identical to the torso of a small toy soldier. The mandrel was coated with boron nitride as a parting agent and placed in our e-beam evaporator. The mandrel was exposed to vapor from an aluminum-bronze source for about 14 hours which was sufficient to deposit approximately one inch of condensate. 
After the vaporization process the condensate shell was removed from the mandrel, mounted on an appropriate block and run as the cavity half in a plastic injection molding machine producing 5000 plastic toy parts. Figure 4 is a photograph of the mold insert and the toy soldier torso produced. Examination of the insert after production indicated very little if any wear implying that it would be good for thousands of more parts. The quality of the parts and the reproduction of details was excellent indicating that this technique would have strong possibilities in the plastic injection molding industry.

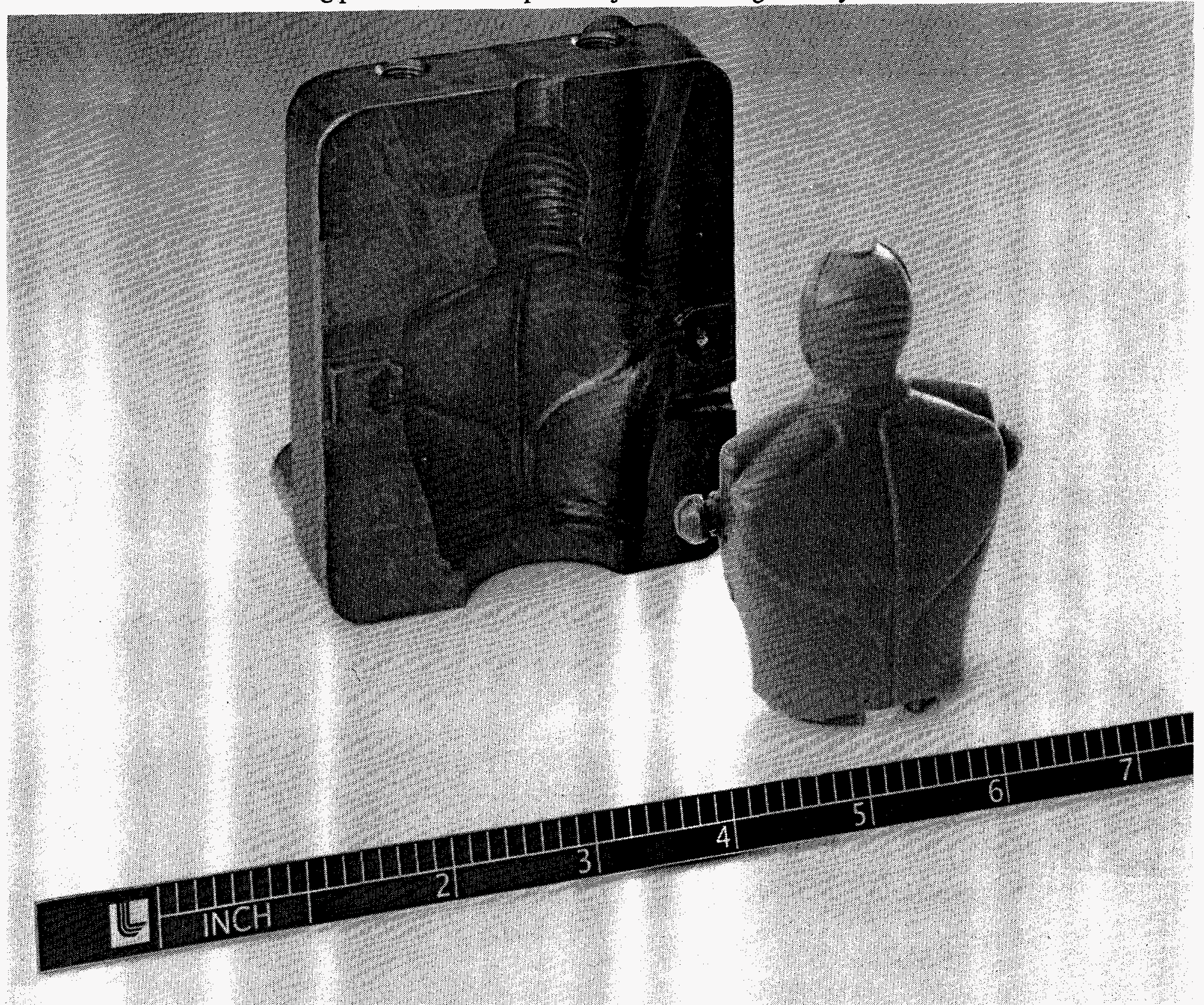

Figure 4. Photograph of cavity mold insert produced using EBPVD technique. 5,000 plastic toy solider parts were produced with this insert. 


\section{Issues}

At present this technology is in its infancy and there are a number of issues which need to be addressed before it can become economically viable. In the die casting industry dies are usually made from alloys, such as tool steel, which posses properties advantageous to the application. In an EBPVD technique these alloys must be vaporized onto a mandrel to produce the dies. Although the vaporization of alloys is possible it is more difficult than the vaporization of single element materials. Figure 5 shows the vapor pressure curves for a number of elements which are important in the tooling industry. The vapor pressure curve of a given element determines how readily the element vaporizes, the higher the pressure the easier it is to vaporize. Covaporization of two elements is possible if the elements have similar vapor pressures. An aluminum-bronze alloy was chosen for the mold insert project because both aluminum and copper have very similar vapor pressures (See Figure 5). In general if the vapor pressures of two elements are within a factor of 100 of each other then covaporization will generally be successful. If not, the high pressure material will vaporize at the expense of the low pressure material and the stoichiometry of the condensate will be different than the evaporant. Alloys, such as 304 stainless steel should be straightforward to vaporize and preserve stoichiometry because its constituents, $\mathrm{Fe}, \mathrm{Ni}$ and $\mathrm{Cr}$ have similar vapor pressures whereas others, such as tool steel, will be difficult because of the carbon which is very difficult to vaporize.

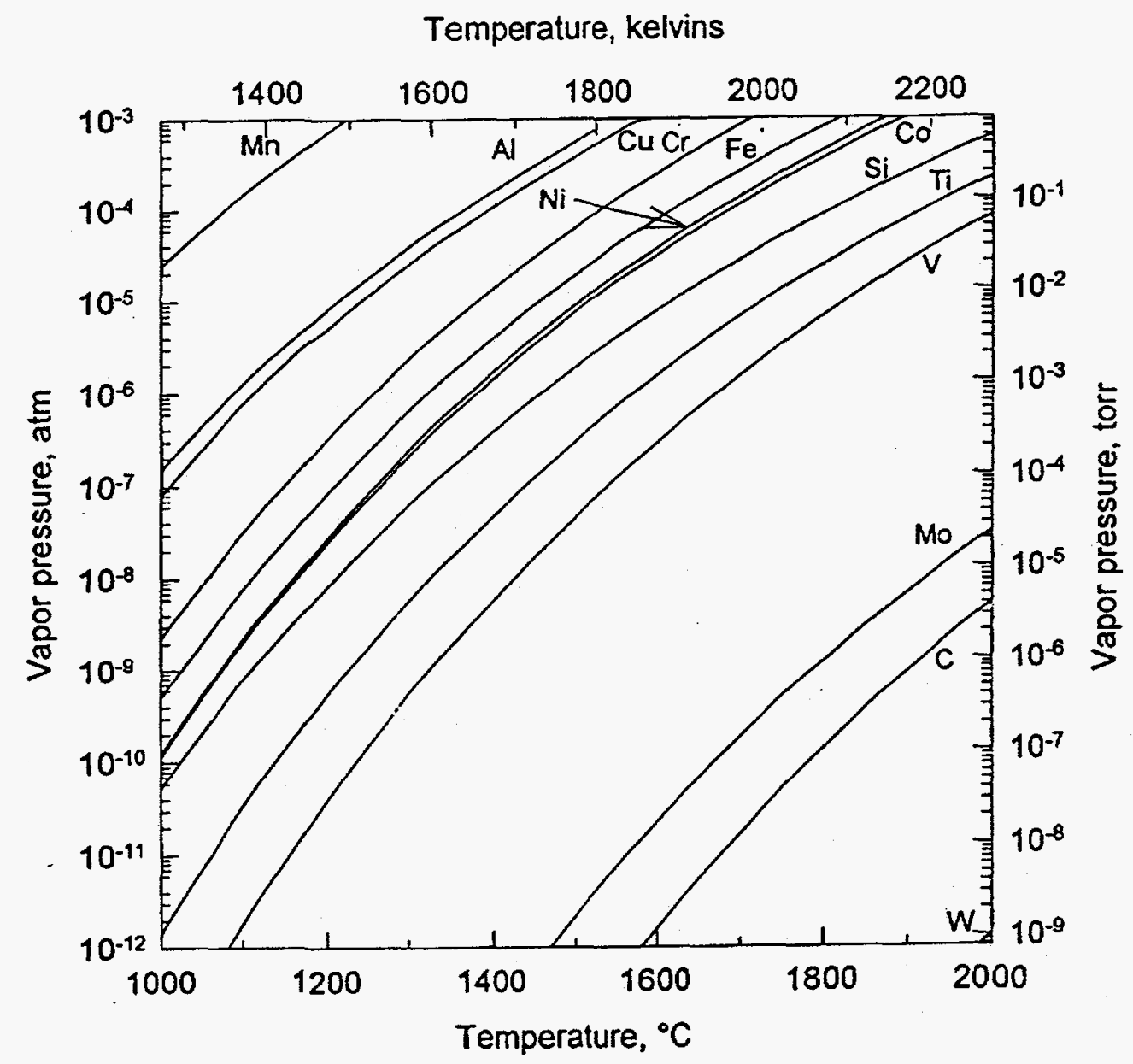

Figure 5. Vapor pressure versus temperature for elements common in industrial alloys. 
One way to mitigate this is to use a multiple source vaporization as shown in Figure 6. Elements of high vapor pressure are contained in one crucible while low vapor pressure elements are contained in the other. The electron beam is time shared between the two crucibles in such a way as to produce the correct stoichiomentry on the mandrel. Although this technique is not new it would require a "tune-up" phase to determine how the e-beam would be shared between the two crucibles.

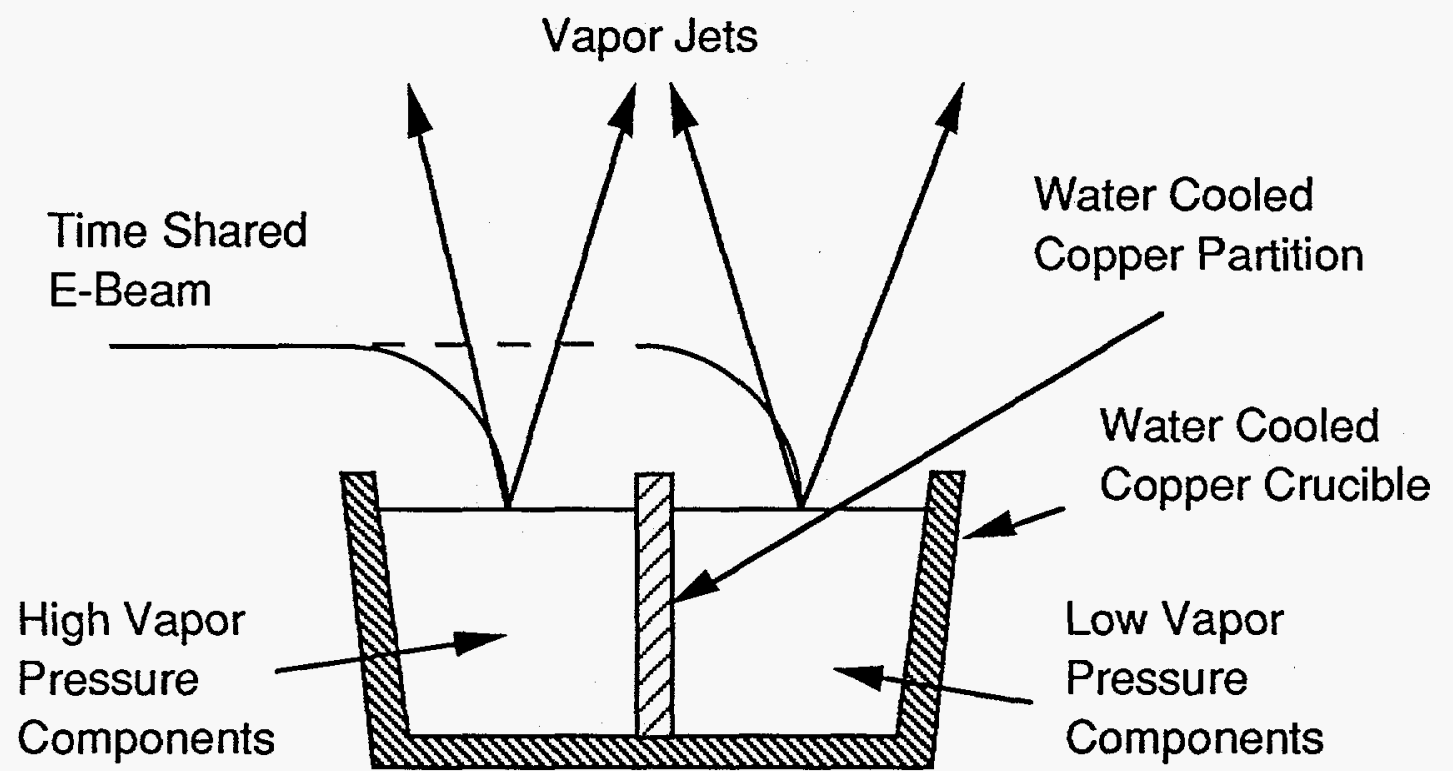

Figure 6. Schematic of dual source vaporization technique used for the vaporization of alloys whose elements have widely disparate vapor pressures.

Dimensional stability is another issue which needs to be addressed. To ensure fully dense deposits the mandrel must be run at high temperatures. If there is a large difference in the coefficients of thermal expansion (CTE) between the mandrel and condensate this will lead to dimensional changes during cool down. For example, the CTE difference between aluminum-bronze and graphite is $12 \times 10^{-6} \mathrm{C}^{-1}$ so that a one inch dimension would be out of specification by $\sim 10$ mils if the deposition occurs at $1123 \mathrm{~K}$. This can in principal be corrected by properly machining the mandrel. Another approach would be to run the mandrel cooler and obtain fully dense deposits by using plasma assisted vapor deposition. In this process the ionization level of the vapor is enhanced by a discharge process near the source while the mandrel is biased negative to give ions additional energy when they collide with the mandrel. This additional energy replaces the thermal energy lost by running the mandrel cooler and gives the atoms enough energy to migrate on the surface to fill in voids.

EBPVD is a line-of-sight process which means that surfaces directly exposed to the vapor will be coated while hidden surfaces or undercuts will be coated only slightly or not at all. Figure 7 is a simulation for the filling of a $1 \mathrm{~cm}$. wide by $1 \mathrm{~cm}$. deep slot by EBPVD. Two cases are represented, one for a Mach number of 7 the other a Mach number of 2 . In this case the Mach number represents the ratio of forward velocity to the random thermal velocity. A higher Mach number flow is more forward directed and hence more line-ofsight. As can be seen the corners of the slot are coated at a slower rate compared to the center of the slot and the surfaces at the top of the slot. As a result a die created this way will have some thin spots which should be backfilled in some fashion to preserve strength. 


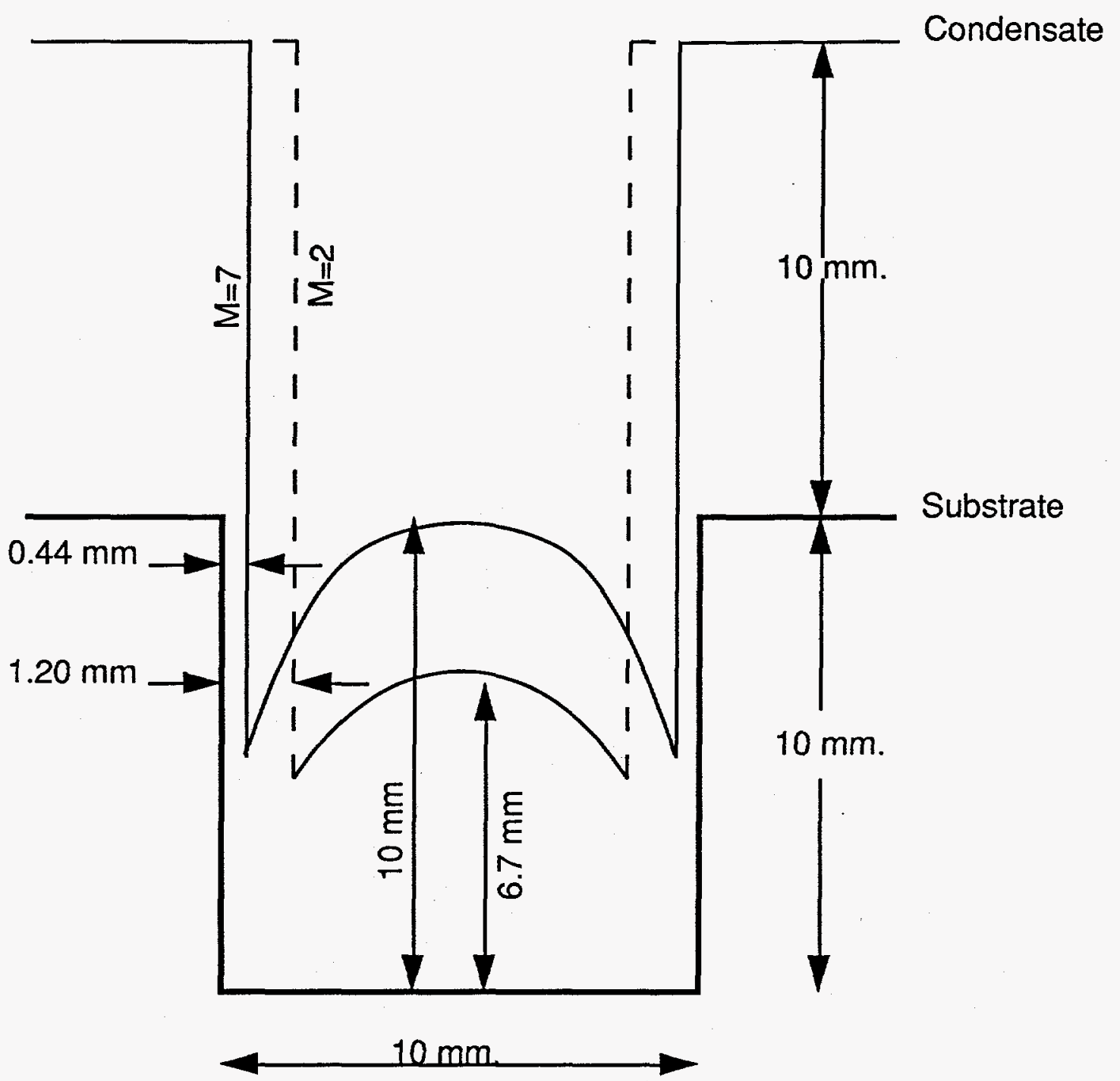

Figure 7. Schematic of how a $1 \mathrm{~cm}$. by $1 \mathrm{~cm}$. slot would coat using an EBPVD process. Vapor flow is incident from the top. The solid line represents a flow with a mach number of 7 while the dashed line represents a mach number of 2 .

Finally there is the issue of the mandrel. If its just as much work to machine the mandrel as it would be to directly machine the die or insert then there is no advantage to using this technique. Techniques and materials must be developed, such as various rapid prototyping techniques, where the mandrel can easily be fabricated and is no longer an issue. One such technique currently under development ${ }^{3}$ applies stereolithography to alumina. Fully dense alumina is a good high temperature material which should be compatible with EBPVD.

\section{Work Performed During this Project}

At the start of this project it was unclear to LLNL what the requirements were for the die material. Our candidate materials in order of degree of difficulty were aluminum-bronze, 304 stainless steel and maraging steel. Early in the project the USAMP technical review board declared that aluminum-bronze would be unsuitable for die casting because its too low in both strength and temperature. 
Consequently, our next step was to vaporize 304 stainless steel in order to investigate its vaporization properties. Before any vaporization could be started it was necessary to build a source. This was done by placing bars of stainless material in the bottom of our water cooled copper crucible and melting them with the e-beam. As the bars melted more stainless was fed to the crucible until the crucible was filled to a level suitable for vaporization. During the process it was observed that a considerable amount of hydrogen was evolved from the source. It is believed that hydrogen became trapped in the stainless during a pickling process. This excessive hydrogen release made it difficult to operate the e-beam gun because of high voltage arcing. Preheating the feedstock to drive off the hydrogen before vaporization could alleviate this problem.

In the subsequent vaporization run a flat graphite plate coated with boron nitride approximately $50 \mathrm{~cm}$. above the source was exposed to vapor for 5.5 hours. During this time $40 \mathrm{kG}$ of stainless steel was vaporized producing an average coating thickness on the plate of $5 / 8$ inch. The average evaporation rate was $7.3 \mathrm{kG} / \mathrm{hr}$ while the average coating rate was 1.9 mils per minute. The e-beam power was $122 \mathrm{~kW}$ while the substrate temperature was kept near $850^{\circ} \mathrm{C}$.

After the run, when everything had cooled down, the vessel was opened and the mandrel and condensate removed. It was immediately noticed that the boron nitride was not as successful here as it had been for the aluminum-bronze case. The stainless was well adhered to the graphite, probably because of carbon diffusion from the graphite. After the stainless and graphite were separated it became apparent that the stainless plate, approximately 6 inches on a side, was warped $\sim 1 / 8$ inch. The amount of warpage could be explained quantitatively by assuming that the stainless and graphite adhered to one another during cool down and the combination bowed due to mismatch in coefficients in thermal expansion.

Table 1 shows the stoichiometry of the condensate, feedstock and specifications for 304 stainless steel. As can be seen the condensate stoichiometry is very close to that of the feedstock and well within the specs for 304 stainless. This is encouraging but not surprising since $\mathrm{Fe}, \mathrm{Cr}$ and $\mathrm{Ni}$ all have vapor pressures which are close (see Figure 5).

Table 1.

Elemental Analysis of Feedstock and Condensate for the Stainless Vaporization Run in ETF

Element

Location

$\underline{\mathrm{Mn}}$

Cr

$\underline{N i}$

$\underline{\mathrm{Si}}$

Fe

Feedstock

$1.67 \%$

19.5

10.1

0.63

68.1

Condensate

$0.6 \%$

19.0

8.4

0.12

71.9

Spec

$<2.0$

18-20

8-10.5

$<1.0$

Although it appears that 304 stainless can be successfully evaporated and full stoichiometry maintained it was decided that stainless was not a viable candidate for die casting. The reasons given were that the coefficient of thermal expansion was too high and the thermal conductivity too low. This combination leads to heat checking or fatigue cracking during operation. Consequently, further investigations using stainless were dropped. 
Our third choice of alloys was maraging steel. This has properties suitable for the die casting industry but is more difficult in terms of vaporization because of the molybdenum which has a very low vapor pressure (See Figure 5). Nevertheless a maraging steel source was built, in a way identical to that described above for the stainless source, but with considerably less outgassing.

Table 2 shows the stoichiometry of the condensate, feed and melt for the maraging steel vaporization run. As was to be expected the Mo didn't vaporize but remained behind in the melt. The $\mathrm{Fe}, \mathrm{Ni}$ and $\mathrm{Co}$ readily vaporized as evidenced by their high concentrations in the condensate. It is surprising that the Al concentration in the condensate wasn't higher than that in the feedstock since its vapor pressure is the highest of all the elements in maraging steel. Finally it is surprising that very little Ti vaporized for its vapor pressure is within a factor of 10 of $\mathrm{Fe}, \mathrm{Cr}$ and $\mathrm{Ni}$. As a result the condensate was something different than maraging steel with unknown properties.

Table 2.

Elemental Analysis of Feedstock, Condensate and Melt for the Maraging Steel Vaporization Run

$\begin{array}{lllllll}\begin{array}{l}\text { Element } \\ \text { Location }\end{array} & \underline{\mathrm{Al}} & \underline{\mathrm{Mo}} & \underline{\mathrm{Ti}} & \underline{\mathrm{Co}} & \underline{\mathrm{Ni}} & \underline{\mathrm{Fe}} \\ \text { Feedstock } & 0.15 & 5.0 & 0.6 & 9 & 20 & 65 \\ \text { Condensate \#1 } & 0.06 & <.01 & <.01 & 8 & 18 & 74 \\ \text { Condensate \#2 } & 0.05 & <.01 & <.01 & 8 & 15 & 76 \\ \text { Melt } & 0.2 & 11 & 0.6 & 11 & 24 & 51\end{array}$

Before closing this section it is important to discuss the thermal fatigue sample which is one of the specimens that we were to produce for testing. Although we did not attempt to make this sample it is important to understand why for it points out one of the limitations of this process. The thermal fatigue sample was a 2" $\mathrm{2} 2$ " $\mathrm{x} 7$ " block with a hole drilled down the center. Figure 8 shows the mandrel required for building such a specimen using EBPVD. To fill up the entire cavity one would have to deposit $\sim 4$ inches of deposit because of the low deposition rate in the corners previously discussed. Although this can be done in principle, it would take close to two full days of vaporization. EBPVD is not suitable for producing large monoliths. It is much better for picking up fine features of small objects.

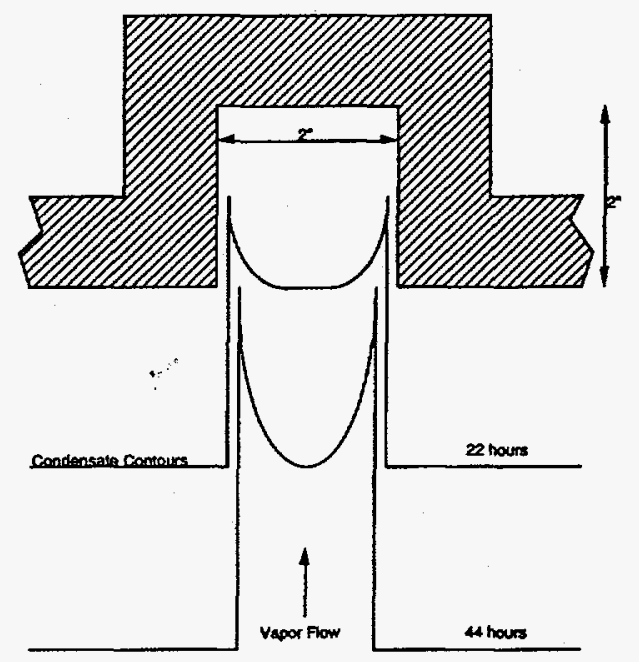

Figure 8. Condensate build up in a mandrel that would be used to produce the thermal fatigue sample. To produce a $2 " \times 2$ " monolith would take $\sim$ two days of continuous vaporization. 


\section{Summary and Conclusions}

EBPVD has been shown to be viable for small parts in the plastics injection molding industry. This process lays down condensate atom by atom and as a result is able to pick up very fine features as opposed to some spraying processes where globules are deposited on the substrate. In addition the requirements for the inserts are somewhat modest in terms of strength, hardness and temperature so that alloys such as aluminum-bronze would be suitable. It is likely that this technique has a niche in this area.

When one tries to apply this technique to other areas, such as die casting where the requirements are more stringent, then several issues arise. Vaporizing tool steels, as required by the die casting industry, is considerably more difficult than aluminum-bronze because the tool steels contain carbon or molybdenum which have very low vapor pressures and are difficult to vaporize. It is likely that this can be mitigated by using a dual source vaporization scheme but requires some development and is not practical for a small $\$ 110 \mathrm{~K}$ project.

Building large monolithic pieces is also not a good practical use of EBPVD. Although the deposition rates are fairly high, 1-2 mils/min, it would take at least two days to build up a sample piece as required by the thermal fatigue sample. EBPVD would be useful where fine features are required and the condensate shell can be reinforced by some filler material.

In addition to the two issues discussed above which were uncovered during this project there exist others which have to be addressed. These include the inability to coat mandrels with undercuts, the necessity to maintain high mandrel temperatures and the development of techniques to cheaply produce mandrels suitable for EBPVD. There are approaches to resolve these issues but their resolution will require a development program.

\section{References}

1. B.A. Movchan and A.V. Demchisin, Fizika Metall. 28, 653 (1969)

2. G.M. Heestand et. al., 27th International SAMPE Technical Conference, Vol 27, edited by Martinez, Arris, Emerson and Pike, 996 (1995)

3. Michelle L. Griffith and John W. Halloran, 27th International SAMPE Technical Conference, Vol 27, edited by Martinez, Arris, Emerson and Pike, 970 (1995)

ST 96-035/GMH:dlb

UCRL-CR- 



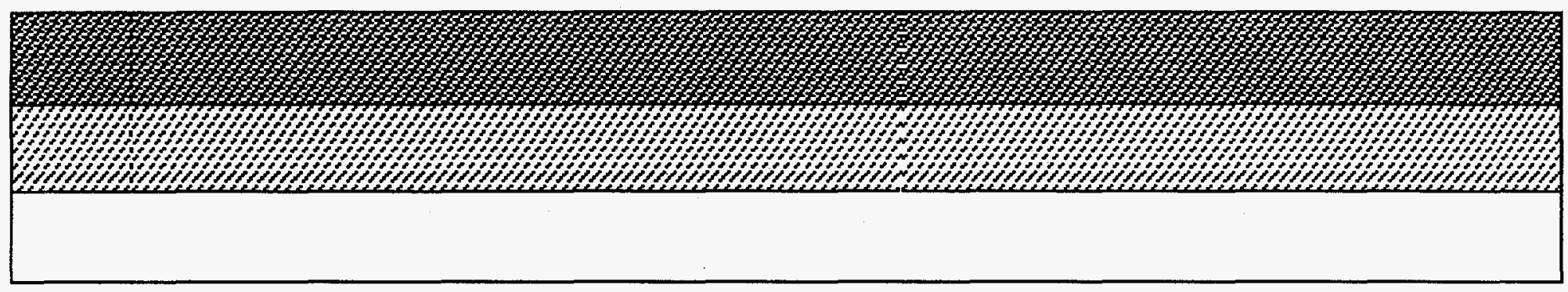

 